\title{
The Cluster approach to the formation of innovative susceptibility priorities within the framework of the Euroconcept «Green U-turn» to renewable energy in Ukraine
}

\author{
Viktor Diuzhev ${ }^{1 *}$, Stanislav Suslikov ${ }^{1}$, Olga Savchenko ${ }^{1}$, Viktoriia Matrosova ${ }^{1}$, and \\ Victoria Veriutina ${ }^{1}$ \\ ${ }^{1}$ National Technical University «Kharkiv Polytechnic Institute», 2 Kyrpychova, 61002, Kharkiv, \\ Ukraine
}

\begin{abstract}
An article discusses the formation of innovative susceptibility of Ukrainian enterprises to the technologies of non-traditional renewable energy. The relevance of this problem is determined on the basis of the European concept of «Green U-turn», which is a logical continuation of the strategy «20-20-20» on the development of non-traditional renewable energy. The article proposes the use of a cluster approach to systematization, grouping and balancing general and specific factors that form the innovative susceptibility of Ukrainian enterprises to technologies of non-traditional renewable energy. The study is based on the expert information regarding stages of life cycles "production-consumptionutilization» of the various non-conventional renewable energy technologies, as well as the analytical information on publication activity as an important factor in the integral assessment of the priorities of energysaving technologies. The estimates are formed taking into account the data on a sample of enterprises in Ukraine. The results of the study will serve as the basis for the formation of appropriate organizational and managerial clusters that allow enterprises to create an innovative product and thereby increase their competitiveness, which is a powerful incentive for national and regional development. Based on this integrated approach, it is possible to analyze factors both at regional level and at level specific enterprise.
\end{abstract}

\section{Introduction}

In the context of a worldwide growing deficit and a corresponding increase in the cost of energy resources, the growth of environmental and technogenic problems, one of the urgent and promising areas of energy conservation is the use of alternative energy sources. These provisions are reflected in a number of scientific works [1,2]. The works show the interconnection of ecological and economic interactions, emphasize the need for their comprehensive accounting and assessment.

${ }^{*}$ Corresponding author: ekosistema909@gmail.com 
In works [3, 4], an assessment of the factors influencing the efficiency of renewable energy sources on the sustainable development of enterprises was made. The necessity of a socio-economic, ecological approach and the use of estimated efficiency indices is substantiated.

In articles [5, 6], the potential of «green energy» is considered in the context of regional initiatives. At the same time, it is proposed to focus on the application of the cluster approach with the subsequent formation of organizational and managerial associations to improve the efficiency of renewable energy technologies.

The authors $[7,8,9]$ propose to use retrospective forecasting of energy systems taking into account renewable energy technologies. They show the need to take into account the peculiarities of energy generation from renewable energy sources in a common complex with traditional energy sources, which increases complex sustainability and energy efficiency.

The relevance of the problematic for the formation priorities of innovative susceptibility within the framework of the concept for the development of «green energy» can be represented in a comparative analysis of the development trends of various energy resources in Ukraine and the world (Table 1).

Table 1. Comparative characteristics of energy consumption (in exajoules) from various energy resources of Ukraine (UA) / Europe (EU).

\begin{tabular}{|c|c|c|c|c|c|c|c|c|c|c|c|c|}
\hline \multirow[t]{2}{*}{ Year } & \multicolumn{2}{|c|}{ Oil } & \multicolumn{2}{|c|}{ Natural Gas } & \multicolumn{2}{|c|}{ Coal } & \multicolumn{2}{|c|}{$\begin{array}{l}\text { Nuclear } \\
\text { energy }\end{array}$} & \multicolumn{2}{|c|}{$\begin{array}{l}\text { Hydro } \\
\text { electric }\end{array}$} & \multicolumn{2}{|c|}{ Renewables } \\
\hline & UA & EU & UA & EU & UA & $\mathrm{EU}$ & UA & EU & UA & $\mathrm{EU}$ & UA & EU \\
\hline 2011 & 0,57 & 30,79 & 2,02 & 20,89 & 1,74 & 15,99 & 0,84 & 9,55 & 0,1 & 5,31 & 0 & 4,12 \\
\hline 2012 & 0,55 & 29,76 & 1,87 & 20,37 & 1,79 & 16,34 & 0,84 & 9,26 & 0,1 & 5,8 & 0,01 & 4,78 \\
\hline 2013 & 0,52 & 29,23 & 1,72 & 19,96 & 1,73 & 15,81 & 0,77 & 9,09 & 0,13 & 6,1 & 0,01 & 5,24 \\
\hline 2014 & 0,44 & 28,64 & 1,45 & 18,0 & 1,49 & 14,84 & 0,81 & 9,09 & 0,08 & 5,9 & 0,02 & 5,62 \\
\hline 2015 & 0,39 & 29,33 & 1,15 & 18,33 & 1,14 & 14,2 & 0,8 & 8,82 & 0,05 & 5,79 & 0,02 & 6,3 \\
\hline 2016 & 0,41 & 30,04 & 1,13 & 19,35 & 1,36 & 13,68 & 0,73 & 8,53 & 0,07 & 5,9 & 0,02 & 6,4 \\
\hline 2017 & 0,42 & 30,6 & 1,09 & 20,12 & 1,08 & 13,23 & 0,77 & 8,43 & 0,08 & 5,26 & 0,02 & 7,12 \\
\hline 2018 & 0,41 & 30,46 & 1,10 & 19,73 & 1,15 & 12,92 & 0,76 & 8,37 & 0,09 & 5,77 & 0,02 & 7,5 \\
\hline 2019 & 0,44 & 30,4 & 1,02 & 19,95 & 1,10 & 11,35 & 0,74 & 8,28 & 0,06 & 5,64 & 0,05 & 8,18 \\
\hline
\end{tabular}

Source: based on $[10,11]$.

However, despite the presented global trends in Ukraine, the use of non-traditional renewable energy technologies is at an early stage. This is due to the presence of a wide range of subjective and objective problems that are found both in the external and internal environment of enterprises, forming a low level of innovative perception of energy-saving technologies. To a large extent, this is determined by insufficient understanding of the innovative potential of non-traditional renewable energy technologies, including its integrated socio-economic and environmental-technogenic efficiency. This statement can be illustrated by the example of the comparative level of state support for renewable energy technologies in Ukraine and Europe at different stages of the life cycle (Table 2).

Based on the analysis of the table, it can be seen that in world practice, state support for renewable energy technologies is much more relevant than in Ukraine. This is facilitated by the assessment of corporate (19/5) and multi-level innovation (13/1) susceptibility. This practice constrains the potential for the formation of innovative susceptibility to renewable energy technologies. In addition, data on the types of state support for renewable energy technologies indicate that advanced economies (especially European ones) are implementing the «Green U-turn» concept, which manifests itself in the implementation of the «20-20-20» plan and is transformed into a sustainable strategy for decarbonizing energy generating capacities (taking into account the life cycle of energy resources) $[12,13]$. 
Table 2. Results of the analysis of the forms of state support along the chain of reproduction of renewable energy sources in world and Ukrainian practice, with the determination of the levels of corporate (1) and multilevel (2) innovative susceptibility.

\begin{tabular}{|l|c|c|c|c|}
\hline \multicolumn{1}{|c|}{ Forms of external support } & \multicolumn{3}{|c|}{ World } & \multicolumn{2}{c|}{ Ukraine } \\
\cline { 2 - 5 } & 1 & 2 & 1 & 2 \\
\hline Public funding & - & + & - & - \\
\hline Support for private R\&D funding & $-/ 0$ & $+/ 2$ & $-/ 0$ & $-/ 0$ \\
\hline Exemption from tax on the purchase of equipment & + & + & - & - \\
\hline Exemption from tax on equipment and property & + & - & - & - \\
\hline Tenders, auctions for construction of objects & + & - & + & - \\
\hline Public procurement of equipment & + & + & - & - \\
\hline State loan guarantees & + & + & - & - \\
\hline Tax benefits & + & - & - & - \\
\hline $\begin{array}{l}\text { Privileges, loans for equipment. Partial return on investment and } \\
\text { accelerated depreciation }\end{array}$ & $+/ 7$ & $-/ 3$ & $-/ 1$ & $-/ 0$ \\
\hline «Voluntary» programs & + & - & - & - \\
\hline Energy tax benefits & + & + & + & - \\
\hline Certificates, fines & + & + & + & + \\
\hline Special bonuses, environmental bonuses & + & - & - & - \\
\hline Additional energy taxes & + & - & - & - \\
\hline Portfolio standards, quotas & + & - & - & - \\
\hline Special procurement tariffs for electricity, «green tariffs» & $+/ 7$ & $+/ 3$ & $+/ 3$ & $-/ 1$ \\
\hline $\begin{array}{l}\text { Administrative measures that oblige the grid to connect new capacity } \\
\text { and buy electricity at a fixed price }\end{array}$ & + & - & + & - \\
\hline State financing of power grid reconstruction & $+/ 2$ & $-/ 0$ & $+/ 2$ & $-/ 2$ \\
\hline Grants to compensate for the cost of power plants & + & + & - & - \\
\hline $\begin{array}{l}\text { Contractual obligations on mutual settlements («return to the } \\
\text { network») }\end{array}$ & - & + & - & - \\
\hline Low interest rates on loans for the purchase of equipment & + & + & - & - \\
\hline Tax incentives and bonus payments for energy & $+/ 3$ & $+/ 4$ & $-/ 0$ & $-/ 0$ \\
\hline State funding of special programs & $-/ 0$ & $+/ 1$ & $-/ 0$ & $-/ 0$ \\
\hline Final values & 19 & 13 & 5 & 1 \\
\hline
\end{tabular}

Source: based on $[14,15]$.

This is due to the relevance in the development of priorities for innovative susceptibility to renewable energy technologies in Ukraine. In particular, this concerns the application of clustering algorithms to identify typical groups of technologies based on renewable energy and the formation of a market for energy-saving technologies.

\section{Methods}

In the scientific literature, especially economic, there are various interpretations of cluster analysis. The authors $[16,5,6]$ agree that the grouping of objects largely depends on the objectivity of assessments in a particular field of study. In the natural sciences, this process is provided by objective constants. In the socio-economic sphere, expert assessments predominate, which by definition have a situational and probabilistic nature.

The methodological approach is aimed at identifying the main theoretical and methodological provisions of the mechanism for the formation of priorities for renewable energy technologies through understanding the complex of environmental-technogenic and socio-economic interaction.

This study uses cluster analysis as an approach that allows us to search for and implement new opportunities for the development of energy-saving technologies and, on this basis, increase the competitiveness and welfare of society. 
The use of cluster analysis made it possible to process data, determine conceptual schemes for the formation and grouping of criteria, form the priorities of renewable energy technologies, in terms of energy saving potential.

The methodological logic of research using the cluster approach can be formulated as follows:

1. Allocation of classes (groups) of renewable energy technologies, from the initial set of energy-generating technologies, based on them, a feature description with its own set of characteristics that determine the typology of the life cycle of fuel resources (research, extraction, primary processing, transportation, accumulation, processing, delivery to power generating facilities, consumption, disposal).

2. Systematization and grouping of specific factors necessary for clustering and further formation for innovative susceptibility of enterprises to renewable energy technologies: climatic, technical, economic, environmental, technogenic, external and internal factors for Ukraine, etc.

3. Formulation of axiometric provisions for analyzing the priorities of renewable energy and, on their basis, an assessment scale of the level of impact of specific factors on the innovative susceptibility of enterprises to renewable energy.

4. Collection of expert and analytical information on the peculiarities of the implementation of the potential of renewable energy, taking into account the factors of the internal and external environment of the enterprise.

5. Analysis for the level of influence a complex factor for each group of renewable energy technologies in relation to enterprises and the formation of a generalized assessment for the group.

6. Formation of a balancing matrix-scheme to assess the influence of factors including the potential of negative and positive impacts by groups of factors.

7. The final balance for the potential of negative and positive impacts by cluster groups of renewable energy and specific factors.

For a systemic generalized characteristic of the potential of factors affecting the innovation susceptibility of enterprises to the technologies of renewable energy, this assessment toolkit is sufficient.

\section{Presentation of the main research material}

Innovative susceptibility as a socio-economic category is based on a multilevel approach, including the property of a step-by-step dynamic increase in the level of awareness and perception of a complex of possibilities. This leads to the formation of a motivated readiness to use energy saving technologies. The level of innovative susceptibility depends on taking into account a complex of factors of the external and internal environment, and in relation to the innovative susceptibility of non-traditional renewable energy (NRE) technologies and the specifics of the life cycle of these technologies [17].

The results of the analysis of the system-factors, from the point of view of the formation of the innovative susceptibility of enterprises to various areas of renewable energy, shows that there are a large number of specific factors of the innovative impact from the potential of renewable energy on specific production, economic and environmental-technogenic systems that use this potential. According to the prevailing opinion about the potential of renewable energy, as a set of beneficial effects on the production and economic system of an enterprise, it is concluded that as a result of the refusal to use traditional energy resources at a particular facility, not only an economic effect is manifested, but also other types of beneficial effects. For example, the ecological effect is manifested as a result of reducing environmental pollution, the effect of technogenic safety as a result of reducing the risks of operating traditional power generating capacities etc. 
However, along with the positive impact, the direction of the renewable energy also has various negative impacts. Moreover, they can be of both systemic and situational nature, which significantly affects the effectiveness for the application of technologies in specific conditions of production-economic and ecological-technogenic systems.

It is important to know that the study carried out clustering of factors of influence on the production-economic and ecological-technogenic system according to the signs for the formation of innovative susceptibility for enterprises to the technologies of renewable energy consumption, which was carried out through an expert survey among specialists of enterprises and organizations.

The total sample of recipients is presented in the amount of about 100 people, while at one enterprise up to 5 specialists of a narrow group could be interviewed (that is, positions relatively equivalent in terms of their impact on the production-economic and environmental-technogenic system). The sample of enterprises is represented by the following list: OJSC «Turboatom», PJSC «Pivdenkabel plant», PJSC «Kharkiv Bearing Plant», SE plant «Electrovazhmash», OJSC «FED», OJSC «Plant Frunze», OJSC «Ukrgastekhnika», STMEC «Ecosystem», JSC «Zaporizhstal», PJSC «Zaporizhkoks», PJSC «Dniprospetstal», OJSC «Dniprovazhmash», OJSC «Dniprocox» etc.

The analysis was carried out for the selected groups of influence-factors on production and economic and ecological and technogenic systems:

- natural and climatic: the degree of access to energy resources (1.1), the stability of the manifestation of energy resources (1.2), the provision of Ukraine with energy resources (1.3);

- technical: constructional complexity (2.1), operational complexity (2.2), experience in installation and operation (2.3), availability of qualified specialists (2.4), the level of development of special services for non-traditional renewable energy (2.5);

- economic: price of $1 \mathrm{~kW}$ of installed capacity (3.1), the cost of $1 \mathrm{~kW} /$ hour of energy (3.2), cost recovery (3.3), time for design, construction and installation, commissioning (3.4), time for approval in permitting structures (3.5), additional beneficial effects (3.6);

- ecological: the level of environmental load from reducing the amount of traditional fuel burned (4.1), alienation of agricultural land (4.2), violation of the environment of natural landscape zones (4.3), the influence of harmful factors on human health (noise, vibration, electromagnetic, electrostatic, infrared radiation, the air of the working area and atmosphere, etc.) (4.4), impact on flora and fauna (4.5), waste disposal (4.6), other environmental impacts (determined under specific conditions of use) (4.7);

- technogenic: he possibility of unplanned breakdowns, accidents (5.1), stability under conditions of seismic activity (5.2), resistance to unfavorable climatic conditions (5.3), fire safety level (5.4), the level of risks of negative impact on human health (5.5), other technogenic risks (5.6);

- technogenic: unplanned breakdowns, accidents (5.1), stability under conditions of seismic activity (5.2), resistance to unfavorable climatic conditions (5.3), fire safety level (5.4), the level of risks of negative impact on human health (5.5), other technogenic risks (5.6);

- external and internal factors for Ukraine: external - the influence of the world dynamics of the cost for energy resources (6.1), gain of environmental and technological standards (6.2), the level and dynamics of the world development of this direction of renewable energy (6.3), etc. Internal - the level of energy and environmental safety standards (7.1), the level of requirements for technogenic safety (7.2), the level of state and regional support (7.3), the availability of a regulatory and methodological framework, awareness and perception of the balance of positive and negative innovative impacts of non-traditional renewable energy (NRE) technologies (7.4) and etc. 
As a result, the averaged assessments of the potential impact on production-economic and ecological-man-made systems were identified, from the point of view of their positive $\left(F^{+}{ }_{N R E j}\right)$ and negative $\left(F_{N R E j}^{-}\right)$impact. The index of the impact of factors on the priorities of the use of NRE technologies $\left(I^{F}{ }_{N R E j}\right)$ has been formed.

$$
I_{N R E}^{F}=\frac{\sum_{j=1}^{n}\left(F_{N R E j}^{+}-F^{-}{ }_{N R E j}\right)}{\sum_{j=1}^{n} \sum_{k=1}^{m}\left(F^{+}{ }_{N R E j}-F^{-}{ }_{N R E j}\right)}
$$

Based on the results of the analysis, conclusions were drawn on the nature of the impact of specific groups of factors, both for individual renewable energy technologies and for the averaged values of the entire set (Fig. 1).

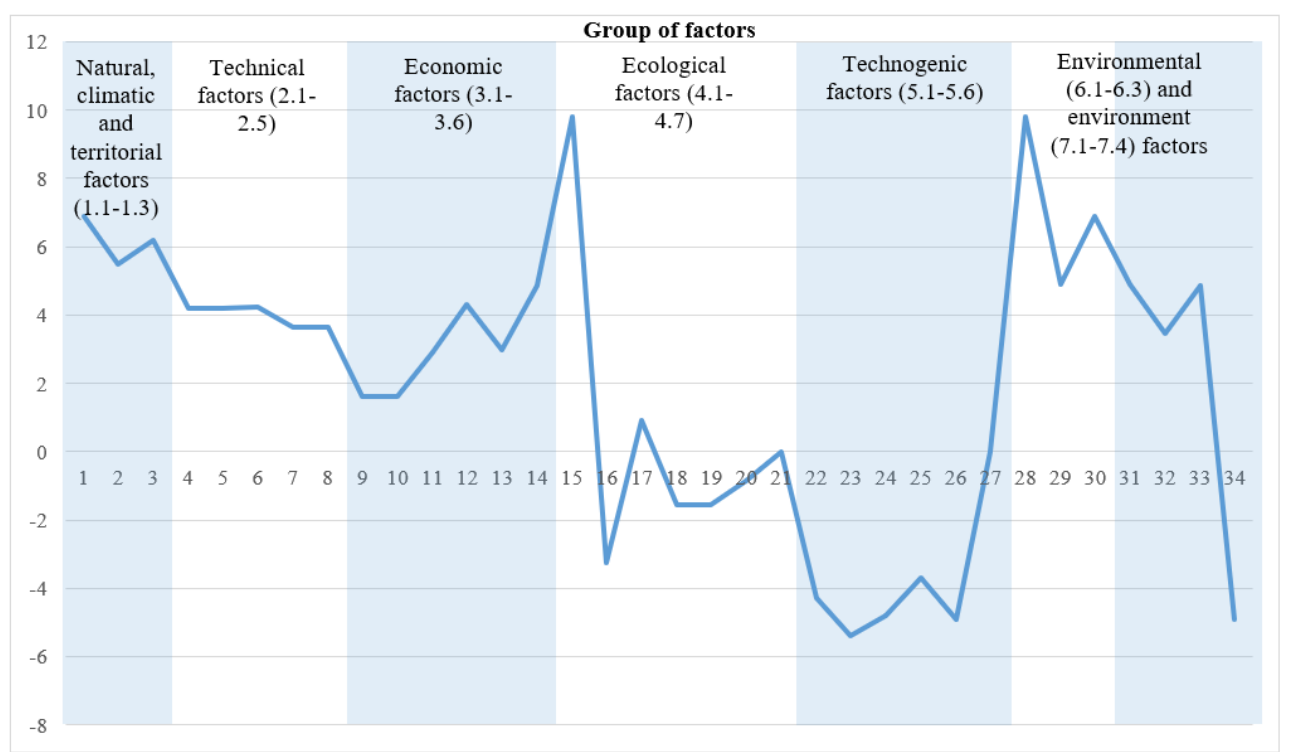

Fig. 1. Impact of specific groups of factors across the entire set of non-traditional renewable energy technologies.

The presented results state for the group of climatic, territorial, technical and economic factors in Ukraine as a whole has a positive balance (2 - 7 units), which is explained by their unambiguous perception and the presence of sufficient publication activity.

The group of environmental factors $(-3-+10$ units $)$ and factors of the internal environment has a versatile assessment with broad dynamics $(-5-+10$ units $)-$ this is facilitated by the presence of a number of negative impacts from certain areas of the nontraditional renewable energy, as well as due to poor disclosure and perception of innovative potential of renewable energy technologies in Ukraine. Therefore, in the future, it is recommended to take them into account in more detail when forming and assessing complex priorities.

Similarly, the group of technogenic factors has a generally negative balance of priorities ( -5 - 0 units). This is due to the fact that the renewable energy technology has a certain technogenic load, being a complex technical structure. 
The analysis of the impact potential on production, economic and ecologicaltechnogenic systems was supplemented by a study of the impact of the information space as a basis for the formation of primary innovation susceptibility. This study is based on the fact that large consumers of energy resources are aware of the need to use energy saving technologies, which forms the primary (subjective) potential of innovative susceptibility. This potential is based on citations and media activity of certain renewable energy technologies on the scale of the Ukrainian information system.

Content analysis of publication activity makes it possible to establish the main vectors of information policy, which consist in an objective reflection of the balance between the number of publications on NRE technologies $\left(Q^{P A}{ }_{N R E i}\right)$, global trends and collective social responsibility. This can be represented as an index of publication activity of renewable energy technologies $\left(I^{P A}{ }_{N R E}\right)[18,19]$.

$$
I^{P A}{ }_{N R E}=\frac{Q^{P A}{ }_{N R E i}}{\sum_{i=1}^{n} Q^{P A}{ }_{N R E i}}
$$

Thus, the actual balance of the positions of renewable energy technologies in the media space reflects an indirect impact on the priorities for non-traditional renewable energy technologies and serves as the basis for the qualitative formation of the following levels of innovative susceptibility.

The procedure for the formation of priorities for non-traditional renewable energy technologies was supplemented by taking into account the number of structural elements within a single life cycle of the "extraction-consumption-utilization" technologies of the renewable energy sector. This made it possible to take into account the impact of additional stages-chains on the amount of additional environmental and technogenic load, which will lead to a decrease in the efficiency of non-traditional renewable energy projects (NRE).

As part of this, an index of the life cycle of renewable energy technologies $\left(I^{L S}{ }_{N R E}\right)$ was formed, which would be defined as the ratio of the maximum value of the stages of the production-consumption-utilization life cycle chains by types of renewable energy technologies $\left(S_{N R E \text { fact }}\right)$ to its actual quantity $\left(S_{N R E \max }\right)$. This index should be used when adjusting the priorities for the balance of positive and negative factors of renewable energy technologies.

$$
I_{N R E}^{L S}=\frac{S_{N R E \max }}{S_{N R E \text { fact }}}
$$

To assess specific factors and their complex impact on the priorities of renewable energy technologies, a complex index of the priorities of production-economic and ecological-technogenic systems to technologies of non-traditional renewable energy $\left(I_{P F}\right)$ was proposed, which would take into account the interaction of the ratio of the balance of beneficial and negative impacts $\left(I^{F}{ }_{N R E j}\right)$, the potential of the publication activity of NRE technologies in the media space $\left(I^{P A}{ }_{N R E}\right)$ and the specific environmental and technogenic load within the life cycle of NRE technologies $\left(I^{L S}{ }_{N R E}\right)$.

$$
I_{P F}=I_{N R E}^{P A} * I_{N R E}^{F} * I_{N R E}^{L S}
$$

The final calculated values produced in the framework of the analysis for balancing the calculation and analytical information and taking into account specific factors for the formation of priorities of production-economic and ecological-technogenic systems to technologies of non-traditional renewable energy are presented in Fig. 2. 


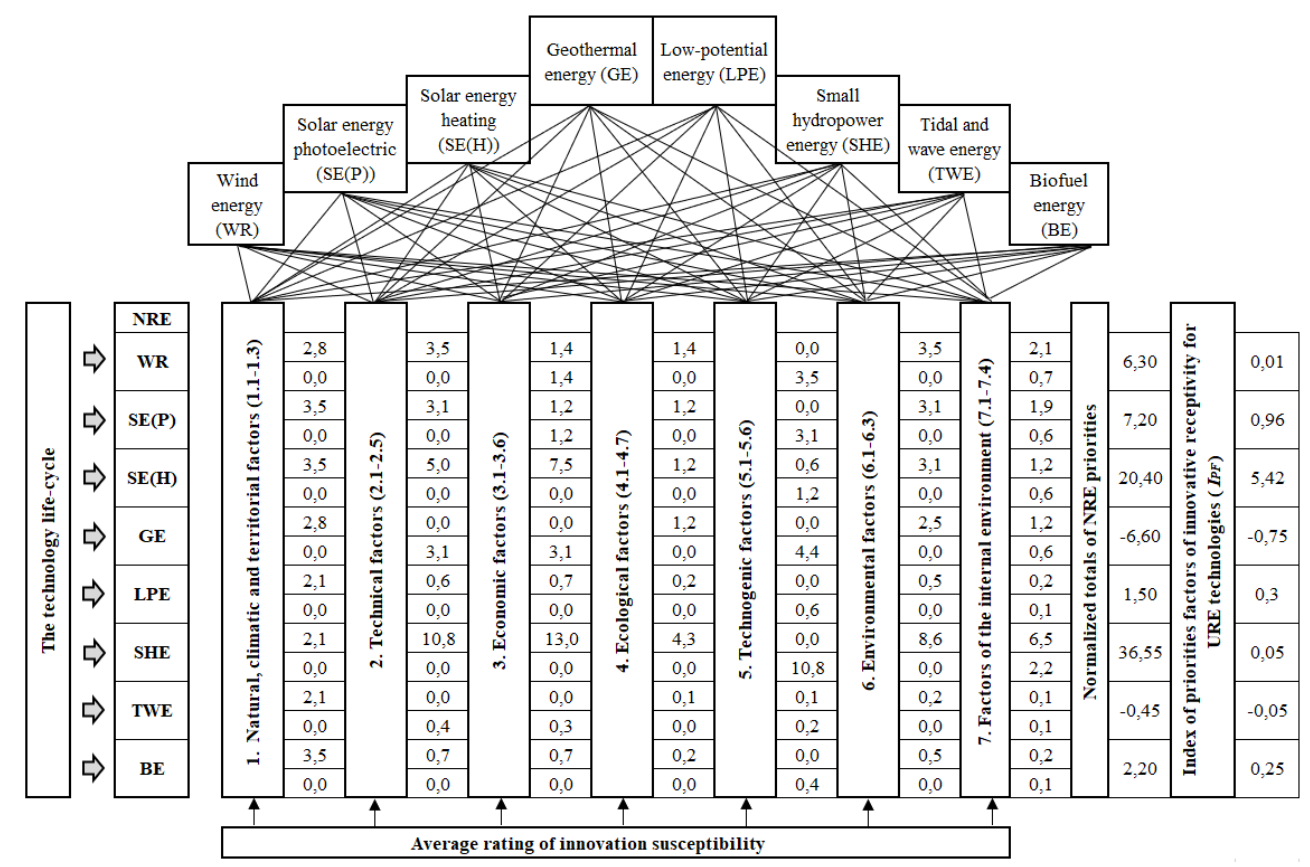

Fig. 2. Systematization and balancing of general and specific factors forming the innovative receptivity of enterprises to non-traditional renewable energy (NRE) technologies.

Based on the results of the analysis of priorities by groups of factors in relation to individual technologies, the following conclusions can be drawn:

1. According to the group of climatic, regional factors, the final assessments for the potential of innovative susceptibility relative to enterprises in various areas of renewable energy have small deviations. The solar energy of the photovoltaic profile, solar energy of the heat generation profile and biofuel have a slight advantage. This is determined by the relative stability, level and availability of the natural and climatic potential of renewable energy in Ukraine.

2. For the group of technical factors, the final estimates differ more significantly: from +11 for small hydropower energy (SHE) to -3.1 for geothermal energy (GE) and -0.4 for tidal and wave energy (TWE). The main reason for the scatter of estimates is the lack of development of the constructive and test base in the direction of tidal-wave energy, as well as the lack of operating experience, qualified specialists, and a weak level of specialized service. Accordingly, various potentials of multilevel innovative susceptibility of enterprises in the areas of renewable energy are being formed.

3. In terms of the group of economic factors, small hydropower energy (SHE) and solar energy heating $(\mathrm{SE}(\mathrm{H}))$ have a greater potential for the formation of innovative susceptibility of enterprises. Tidal-wave and geothermal energy have insufficient potential, which is determined by large specific capital investments in $1 \mathrm{~kW}$ of installed capacity, which entails high costs and slow payback. The potential of tidal-wave energy is the smallest, since there is no proven industrial technology.

4. According to the group of environmental factors, small hydropower energy (SHE) and solar energy have the highest potential.

5. According to the group of technogenic factors, the greatest negative potential exists for small hydropower energy (SHE), geothermal energy (GE) and solar energy heating $(\mathrm{SE}(\mathrm{H}))$. The rest of the areas of renewable energy have a list of technogenic risks, which, 
to one degree or another, do not significantly affect the formation of enterprises' innovative susceptibility.

6. With regard to the group of external and internal factors, there is sufficient potential for the formation of multi-level innovative susceptibility of enterprises in all directions. At the same time, those areas for which there is already a certain level of state support, in particular, the system of «green tariffs», have an advantage.

As a result of the balances of beneficial and negative effects of the above factors, the indisputable leader is the solar energy of the heat generation $(+5.42)$ and photovoltaic profile $(+0.96)$. Low-potential energy (LPE) $(+0.3)$, biofuels $(+0.25)$ have good potential. This is determined by the availability of operating experience, the availability of qualified specialists, as well as good indicators of environmental and technological safety.

The rest of the directions have potential, which can manifest itself in certain situational conditions of use. Geothermal energy (GE) (-0.75) and tidal-wave energetics (TWE) (-0.05) have a negative potential, which is determined by their experimental state and the insufficient (for geothermal energetics) experience on actually operating objects.

\section{Conclusions}

Based on the results of the study, the following conclusions were made. At the heart of the Euroconcept «Green U-turn» is a targeted approach based on a comprehensive understanding of socio-economic and ecological-technogenic interactions. One of the components of this approach is a mechanism for developing priorities for energy supply sources.

Renewable energy technologies stand out among the important priorities of the euro concept, which is confirmed by various levels of government support at different stages of their life cycle. Proceeding from this, the European integration processes dictate to Ukraine the corresponding standards in the field of energy supply based on renewable energy. This gives rise to the need for the formation of national priorities for state support for these technologies.

The paper proposes a cluster approach that provides a comprehensive justification of priorities and serves as the basis for the formation of multi-level innovative susceptibility of enterprises to non-traditional renewable energy. At the same time, the influence of various groups of technologies and specific factors differentiated by them is shown, the analysis of which was carried out on the basis of a methodological approach.

Within the framework of the approach, the balancing of beneficial effects and negative influences was carried out, which made it possible to show the various directions of their implementation in the formation for various levels of innovative susceptibility of enterprises.

It is concluded that the list of factors of the internal and external environment of enterprises (natural and climatic, technical, economic, social, ecological, technogenic) and the assessment of their impact depends on the development of renewable energy technologies, the scale and characteristics of innovative systems for their application, both at the regional level, and at the level of a particular enterprise.

This will serve as the basis for the formation of appropriate organizational and managerial clusters that allow enterprises to create an innovative product and thereby increase their competitiveness, which is a powerful incentive for national and regional development.

This work was conducted within the projects «Research of organizational and economic problems to increase the innovative susceptibility of enterprises to new technologies» (State registration No. 0118U002012) «Increasing the innovative susceptibility of enterprises to energy saving technologies» (State registration No. 0015U007155). 


\section{References}

1. Ryumin1a, Ye. (2016). Ecological Aspects of the Assessment of Quality of Life. Economy of Region, 12 (4), 1113-1122. https://doi.org/10.17059/2016-4-13

2. Babenko, V., Petuhova, V., \& Perepelitsia, A. (2017). Forming of informatization strategic prospects for Ukraine in conditions of world economy globalization. Scientific bulletin of Polissia, 2(10), 24-34. https://doi.org/10.25140/2410-9576-20171-2(10)-24-34

3. Bamzadeh, M.H., Meyar-Naimi, H., \& Moradi, M.H. (2021). A Review of the Impact Factors on Renewable Energy Policy-Making Framework Based on Sustainable Development. International Journal of Renewable Energy Research (IJRER), 11 (1), 473-485. https://www.ijrer.org/ijrer/index.php/ijrer/issue/view/4785074604081194

4. Cirstea, S.D., Moldovan-Teselios, C., Cirstea, A., Turcu, A.C., Darab , C.P. (2018). Evaluating Renewable Energy Sustainability by Composite Index. Sustainability, 10(3). https://doi.org/10.3390/su10030811

5. McCauley, S., \& Stephens, J. (2012). Green energy clusters and socio-technical transitions: analysis of a sustainable energy cluster for regional economic development in Central Massachusetts, USA. Sustainability Science, 7(2). https://link.springer.com/article/10.1007\%2Fs11625-012-0164-6

6. Lowitzscha, J., Hoickab, C.E., \& van Tuldera, F.J. (2020) Renewable energy communities under the 2019 European Clean Energy Package - Governance model for the energy clusters of the future? Renewable and Sustainable Energy Reviews, 122, Article 109489. https://doi.org/10.1016/j.rser.2019.109489

7. Hori, K., Kim, J., Kawase, R., Kimura, M., Matsui, T., Machimura, T. (2020). Local energy system design support using a renewable energy mix multi-objective optimization model and a co-creative optimization process. Renewable Energy, 156, 1278-1291. https://doi.org/10.1016/j.renene.2019.11.089

8. Ghanbari-Mobarakeh, P., \& Moradian, M. (2019). A New Paradigm for Distributed Generation Management Considering the Renewable Energy Uncertainties and Demand Response Resources. International Journal of Renewable Energy ResearchIJRER, 9(1), 215-225.

9. Liutak, O., Baula, O., Poruchnyk, A., Stoliarchuk, Ya, Kravchuk, P., \& Kostynets Iu. (2021). The Development Of Renewable Energy In The Context Of Formation Of Innovative Economy And Energy Independence As The Geopolitical Priorities Of The State. IOP Conf. Series: Earth and Environmental Science, 628, 012012. https://doi.org/10.1088/1755-1315/628/1/012012

10. Cedigaz the International Association for Natural Gas. (2019). World LNG Outlook 2019. https://www.cedigaz.org/category/analysis/

11. BP. (2020). Statistical Review of World Energy (69th edition) [Fact sheet]. https://www.bp.com/content/dam/bp/business-sites/en/global/corporate/pdfs/energyeconomics/statistical-review/bp-stats-review-2020-full-report.pdf

12. Gielen, D., Boshell, F., Saygin, D., Bazilian, M.D., Wagner, N., \& Gorini, R. (2019). The role of renewable energy in the global energy transformation. Energy Strategy Reviews, 24, 38-50. https://doi.org/10.1016/j.esr.2019.01.006

13. Blazquez, J., Fuentes-Bracamontes, R., Bollino, C.A., \& Nezamuddin, N. (2018) The renewable energy policy Paradox. Renewable and Sustainable Energy Reviews, 82 (1), 1-5. https://doi.org/10.1016/j.rser.2017.09.002 
14. REN 21. (2019). Renewables 2020 Global Status Report [Fact sheet]. https:/www.ren21.net/wp-content/uploads/2019/05/gsr_2020 full_report_en.pdf

15. IRENA. (2018). Global Energy Transformation: A roadmap to 2050, International Renewable Energy Agency, Abu Dhabi [Fact sheet]. https://www.irena.org//media/Files/IRENA/Agency/Publication/2018/Apr/IRENA_Report_GET 2018.pdf

16. Danilov, S.V., \& Lukyanova, M.I. (2015). Cluster approach in the regional education. Sovremennyye problemy nauki i obrazovaniya, 1(1). http://www.scienceeducation.ru/ru/article/view?id=18896

17. Dyuzhev, V.G., \& Suslikov S.V. (2015). Formation of priorities of technologies of nontraditional renewable energy in Ukraine from the position of analysis of their life cycles. Problems of economics, 3, 52-58.

18. Jamali, H.R., Azadi-Ahmadabadi, G., \& Asadi, S. (2018). Interdisciplinary relations of converging technologies: Nano-Bio-Info-Cogno (NBIC). Scientometrics, Springer, 116(2), 1055-1073. https://doi.org/10.1007/s11192-018-2776-9

19. Dyuzhev, V.G., Suslikov, S.V., \& Bolshakov, D.V. (2017). Research of trends of alternative energy forms in the context of the world and ukrainian scientific electronic resources' analysis. Visnyk Kremenchuts'koho natsional'noho universytetu im. Mykhayla Ostrohrads'koho, 6 (107), 37-41. 